\title{
Reseña bibliográfica de: Roper, L. (2017). Martín Lutero: renegado y profeta. Madrid: Taurus. $621 \mathrm{pp}$.
}

Palabras clave: Reforma Protestante - Martin Lutero - Historia De La Temprana Modernidad - Sacro Imperio Romano Germánico

Keywords: Protestant Reformation - Martin Luther - Early Modern History Holy Roman Empire

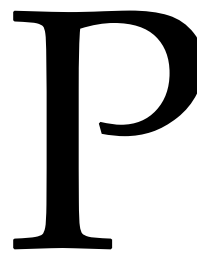

ocos años antes de su muerte, en 1542, Martín Lutero logró conseguir, no sin dificultades, una copia del Corán, y leerlo con gran entusiasmo. Inmediatamente después abogó, frente a varios estupefactos compañeros de la causa evangélica, para que se publicase, lo que finalmente ocurrió al año siguiente con una advertencia escrita por él mismo. Argumentaba que su fe era tan fuerte que podía leer el libro del Turco sin dudar y con el objetivo de conocer a qué se enfrentaba. Esta es tan solo una de las desconcertantes (y por lo tanto fascinantes) poco conocidas historias del reformador que refiere Lyndal Roper (Melbourne, 1956) en la completísima biografía que la editorial Taurus ha puesto a disposición de los lectores de habla hispana.

Es de público conocimiento que el campo teológico es históricamente patriarcal. Esto ha colocado a la biografía (y hagiografía) de los personajes religiosos de Occidente en el coto cerrado de las plumas masculinas (con escasas excepciones) durante siglos, abriéndola a los laicos no hace mucho tiempo y a las historiadoras aún menos. Roper es Doctora y Profesora del Oriel College de la Universidad de Oxford. Se especializa en la temprana modernidad en el Sacro Imperio. Ha estudiado el rol de la mujer en gran profundidad, al igual que el fenómeno de la Reforma protestante. Entre otras obras, Witch Craze: Terror and Fantasy in Baroque Germany (2004) es su otro gran libro, editado originalmente por la Yale University Press, del cual esperamos ansiosos su traducción.

Esta imponente obra enfrenta la clásica pregunta del caso: ¿qué decir de nuevo acerca de Martín Lutero? Quien, junto con Hitler, Julio César, Napoleón, por nombrar solamente algunos, es uno de esos personajes cuyas biografías llenan estantes en varios idiomas, escritas por fieles seguidores, detractores e investigadores serios casi en igual número. De referencia obligada para los lectores en español han sido las escritas por Lucien Febvre y James Atkinson.

La autora comienza explicando lo vital que ha sido para su labor la apertura de los archivos que se encontraban en Alemania Oriental (sabido es que Sajonia, el centro neurálgico de los acontecimientos de la Reforma, se encontraba bajo la República Democrática Alemana). Por lo que el presente trabajo se halla entre los más completos acerca de la vida del monje alemán, con sus ciento cincuenta páginas de aparato crítico,

Anuario de la Escuela de Historia Virtual - Año 11 - N 17 - 2020: pp. 158-161. ISSN: 1853-7049. 1853-7049. http://revistas.unc.edu.ar/index.php/anuariohistoria 
entre notas, fuentes y bibliografía. Además, se propone la elaboración de un perfil psicológico del personaje, analizando su relación con quienes lo rodearon durante toda su vida, poniendo el acento en la relación con sus diversos padres: su padre biológico, Hans Luder; su superior y confesor en tiempos de crisis, Johann von Staupitz, y Dios.

Desde el inicio el lector asiste a una detallada radiografía del ámbito social y económico de la familia de Lutero, en la zona minera de Eisleben. Esta escala no descuida el panorama religioso y político del Electorado de Sajonia ni del Sacro Imperio en su conjunto, como estructuras de poder y disputa. Posteriormente discute de manera crítica las anécdotas (tan difundidas) acerca del origen de la vocación religiosa de Lutero, de las 95 tesis clavadas en Wittenberg, entre otras. Quizás el retrato más completo sea el realizado acerca del sistema universitario tardo medieval, en el cual se desarrolla la parte central de las vidas, tanto de Lutero, como de los demás reformadores que lo acompañaron. Se le concede una importancia similar a la que posee el púlpito. Esta relación entre Academia e Iglesia, como bien ha dicho Rudolf Von Thadden (2002) marcará a las numerosas corrientes reformadas nacionales del norte de Europa hasta nuestros días. Se vislumbra, además, la gran influencia de Guillermo de Ockham en la Universidad de Erfurt, lo cual fue vital en la formación de Lutero como monje, estudiante y profesor.

Las disputas recorren todo el libro, desde Heidelberg y Leipzig hasta Worms, donde el joven monje se enfrenta al también joven Carlos V en 1521. Podría decirse que incluso estas discusiones, que alcanzaban elevados niveles de efervescencia, rigen de alguna forma el índice. Llama la atención la brevedad con la que se trata la disputa epistolar ocurrida con Erasmo de Rotterdam acerca del libre albedrío, conflicto que llegó a dividir la cristiandad y que también ha hecho correr ríos de tinta. Este fue su quiebre definitivo con la filosofía y el humanismo renacentista.

En ciertas ocasiones, Roper se detiene para explicar las consecuencias a largo plazo de ciertas actitudes y acontecimientos que podrían escaparse. Basta mencionar un posicionamiento con respecto a la autoridad y a las Escrituras, para que se nos muestre sus implicancias en el estallido de la Guerra de los Treinta Años o incluso con respecto a la postura civil frente a los crímenes del nazismo. De igual modo, constantemente se advierte el surgimiento de esa otra rama reformada que se desarrolló pasada la mitad del siglo XVI y que será el centro de muchos de los conflictos del siglo siguiente: el calvinismo.

Podría resumirse que en la teología luterana fueron tres enfoques fundamentales los que la separaron de manera tajante de las demás corrientes reformadas: la transustanciación en la misa, el bautismo (el momento de la vida en que se realice) y el ya citado libre albedrío (si tenemos o no decisión o siquiera la posibilidad de cambiar nuestro destino, salvífico o condenatorio). Estas problemáticas, entre muchas otras, dividieron a la cristiandad del centro de Europa durante siglos. El libro pone a disposición los argumentos tanto filosóficos y teológicos como metafísicos dados por los diversos reformadores. Para Lutero en un principio, durante la misa el milagro hacia 
presente la carne de Cristo sin ningún tipo de evocación o metáfora. Con respecto al bautismo, debía hacerse al niño pequeño (aunque después él mismo dude de este tema). Finalmente, según Lutero, los hombres no tienen poder alguno en el plan determinado por Dios acerca de quién logra la salvación y quién no (lo que se encuentra íntimamente conectado con el desprecio que sentía por la búsqueda de la salvación mediante las buenas obras). Algunos de estos puntos resultan problemas espirituales bastante lejanos para la mayoría en la actualidad. En el siglo XVI estos tópicos ocupaban parte importante de la vida (tanto pública como privada) de las personas, alterando profundamente su religiosidad, que permeaba todos los ámbitos.

Por otra parte, resulta fundamental el capítulo acerca del matrimonio y la carne para comprender la mutación del reformador acerca del pecado y del sexo, dado que Lutero (ex monje) se casa en 1525 con Catalina von Bora (ex monja). Este hecho, nada menor, fue de un impacto enorme tanto para católicos como para protestantes. La llamada apertura a la vida sexual (claramente mucho menos de lo que la concebimos hoy) de los pastores luteranos es una de las diferencias que más llaman la atención, dado que el reformador creía que el deseo sexual estaba ahí, puesto por Dios, y que por lo tanto era inevitable y no tenía sentido castigar la carne.

Además, se presenta una esmerada puesta en común de las opiniones de los contemporáneos con respectos a cada disputa o tema, citando lo que da la impresión de ser una inabarcable correspondencia cruzada. Toda obra, teológica o política, dada a la imprenta por Lutero es comentada por la autora, esbozando, además, el impacto que esta tuvo en el naciente público lector que inaugura el siglo XVI. Dentro de dicha apreciación, acerca de la circulación de los textos impresos (toda una novedad), se destaca el uso de grabados e imágenes, antecedentes de la moderna propaganda política. A la cabeza de esta producción se encontraba el taller de los Cranach (padre e hijo) que resultó decisivo a la hora difundir al reformador entre un público más amplio.

Los capítulos finales analizan el problemático carácter (en extremo volátil) del reformador, que termina por alejarlo de numerosas amistades y alianzas, dejándolo prácticamente aislado hacía el final de sus días. Temas más "peliagudos" (en palabra de la autora) son tratados en profundidad, en particular el bien conocido antisemitismo recalcitrante que Lutero desarrolla a partir de, aproximadamente, 1530. La muerte del reformador, ocurrida en 1546 en el mismo lugar donde había nacido, no escapa al análisis: según creencias de la época, la violencia con la que muriera uno estaba relacionada con su vínculo con Dios. Murió en paz, resultando un hecho propagandístico para la causa reformada.

Roper cierra con un breve pero puntilloso análisis de la influencia que ha tenido el luteranismo y sus enfoques en la cultura alemana durante los cinco siglos que nos separan de -o unen a- su inicio. Haciendo énfasis en la música clásica y sus temas, como así también en la literatura, desde el Barroco, pasando por la Aufklärung y el Romanticismo. La obra puede resultar esclarecedora, no solo para los estudiosos de la historia moderna europea, sino para cualquiera que pretenda indagar en el surgimiento 
de las diversas corrientes evangélicas, las cuales se yerguen como actores políticos cada vez más decisivos en el escenario latinoamericano actual.

\section{Referencias bibliográficas}

Atkinson, J (1971). Martin Lutero y el nacimiento del protestantismo. Madrid: Alianza Editorial.

Febvre, L (1956). Martin Lutero, un destino. México: Fondo de Cultura Económica.

Roper, L. (2004). Witch Craze: Terror and Fantasy in Baroque Germany. New Haver: Yale University Press.

Von Thadden, R (2002). Intolerancia y fundamentalismo en la tradición protestante. En F. Barret-Ducrocq (Dir.), La intolerancia (pp. 64-67). Barcelona: Granica.

Ignacio Liziardi Universidad Nacional de Córdoba igna_liziardi@yahoo.com

Para citar esta reseña:

Liziardi, Ignacio (2020): Reseña bibliográfica de: “Roper, L. (2017). Martín Lutero: renegado y profeta. Madrid: Taurus. 621 pp." Anuario de la Escuela de Historia Virtual $17,158-161$. 